\title{
Combat Casualties In The First Decade Of The 21st Century - New And Emerging Weapon Systems
}

\author{
KA Galbraith
}

\begin{abstract}
This paper reviews new and emerging weapons systems targeted directly or indirectly against personnel. It distinguishes emerging technologies that may form the basis of usable weapons in the next 10 years, from the speculations and aspirations of weapons designers, and identifies six groups of weapons systems which will present significant new or changing threats to UK forces. The article combines this information with knowledge of biophysical interactions and clinical effects, to identify possible consequences for the DMS in terms of types, patterns and numbers of casualties. Ballistic threats will continue to be the most common casualty-producing mechanism for servicemen in any environment.
\end{abstract}

\section{Introduction}

Throughout the history of warfare, changes in weaponry have caused dramatic changes in casualty types and numbers, repeatedly presenting military medical services with fresh challenges - sometimes without warning. On occasion, medical services have been able to rise to the challenge; at other times, they have been overwhelmed.

Historical examples of changes in weaponry which have altered types or numbers of battlefield casualties radically are numerous; six examples are given below:

- Emergence of firearms: following millennia of combat with edged or blunt hand weapons and missiles, firearms caused wounds of an unfamiliar type, with a larger amount of tissue damage and contamination. These wounds required notably different surgical treatments.

- Increased accuracy and effectiveness of small arms and fragmenting artillery shells: By the end of the 19th century, nearly $90 \%$ of casualties were due to small arms' bullets and few wounds were caused by edged weapons. Thereafter, the proportion of casualties from small arms declined and the proportion due to fragmentation weapons steadily increased. The use of large numbers of machine guns and artillery pieces against massed infantry in WWI resulted in enormous numbers of casualties in very short periods, overwhelming the medical services and resulting in sub-optimal treatment for many.
- Chemical weapons: the use of 'poison gases' in WWI resulted in large numbers of casualties of a completely unprecedented type.

- Anti-personnel land mines: casualties with the characteristic wounds caused by these weapons were first observed in numbers in WWII, and have been seen in most conflicts since then. Surgical treatment has generally been poor until recent years, and even now is frequently sub-optimal. Mines will continue to pose a real threat to UK servicemen for the foreseeable future.

- Optimised pre-formed fragmentation munitions: these have typically accounted for $70-90 \%$ of all battle casualties in recent conflicts, such as the Gulf War 1991 (see Figure 1). They result in multiple casualties, each with multiple low energy wounds to the limbs. The incidence of wounds to the trunk and head is reduced by personal armours, but the unprotected limbs are particularly vulnerable, as are the eyes.

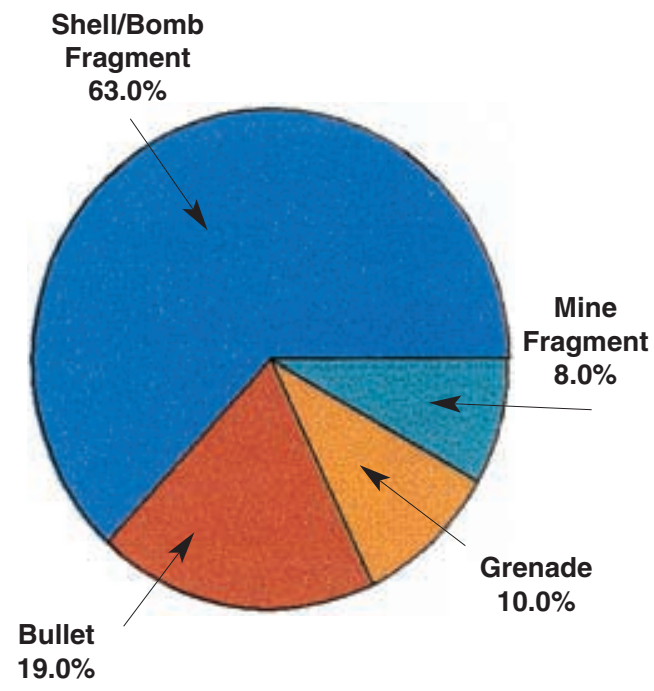

Fig 1. GulfWar 1991: Causes of Wounds, 32 Field Hospital. The majority of the 'grenade' and 'shell and bomb' injuries were from pre-formed fragments.

- Increased incidence of burns and eye injuries: Two notable 20th century trends, which can be ascribed to changes in types of combat and in a range of weapons types, rather than to the development of particular individual weapons, have been the steadily rising incidence of burns and of eye injuries (Table 1 and Table 2). 
Table 1. Historical incidence of burn injuries in 20th century wars.

\begin{tabular}{|c|c|c|}
\hline War & $\begin{array}{l}\text { Incidence } \\
\text { of burn } \\
\text { injury }\end{array}$ & \\
\hline $\begin{array}{l}\text { Historical } \\
\text { incidence }\end{array}$ & $3-4 \%$ & $\begin{array}{l}\text { Data mainly from WW II, } \\
\text { Vietnam }\end{array}$ \\
\hline $\begin{array}{l}\text { Arab-Israeli } \\
1973\end{array}$ & $10 \%$ & Most sustained in AFVs \\
\hline $\begin{array}{l}\text { Lebanon } \\
1982\end{array}$ & $8 \%$ & $\begin{array}{l}\text { Burn casualties reduced } \\
\text { after Israeli forces } \\
\text { improved protective } \\
\text { clothing and AFV design }\end{array}$ \\
\hline $\begin{array}{l}\text { Falklands } \\
1982\end{array}$ & $18 \%$ & $\begin{array}{l}\text { Most sustained in air or } \\
\text { missile attacks on ships }\end{array}$ \\
\hline
\end{tabular}

Table 2. Historical incidence of eye injuries in 20th century wars.

\begin{tabular}{lc}
\hline Conflict & $\begin{array}{c}\text { Eye Injuries as \% } \\
\text { of total casualties }\end{array}$ \\
\hline Crimean & 0.65 \\
WWI & 2 \\
WWII & 2 \\
Six day war 1967 & 5.6 \\
Yom Kippur 1974 & 6.7 \\
Lebanon 1982 & 6.8 \\
Vietnam & 9 \\
\hline
\end{tabular}

New causes of combat injury continue to emerge, due both to the enhancement of existing weapons systems and the development of new ones.

\section{Implications for the Defence Medical Services}

Different types of casualties, in different patterns in terms of numbers and of combinations of injuries, will pose fresh challenges to the Defence Medical Services (DMS), particularly in the areas of:

- Casualty prediction: The extent to which the casualty types, numbers and patterns in a given conflict or operation can be predicted in advance, and therefore whether suitable medical resources can be predicted and deployed in anticipation.

- New/previously unknown injury types: Whether suitable/optimal treatment techniques for certain types of injury exist at all; if they do exist, whether they are available from the DMS in terms of equipment and personnel skills.

- Local overload of medical facilities: The response to temporary local overwhelming of medical resources by unexpected numbers or new types of casualties, produced by new types of weapons.

- Increased incidence of specific types or total numbers of casualties: The response when there are likely to be numbers of casualties too large to permit optimal treatment, or numbers of specific types of casualties too great for the total particular specialist staff and equipment possessed by the DMS. This raises the issue of availability and speed of evacuation. Large numbers of specific types of casualties such as those with retinal haemorrhages could embarrass or overwhelm even NHS abilities to provide optimal treatment for all individuals.

- Research: The need for research and development of new treatments, if they do not currently exist.

\section{Aims}

The aims of this paper are to:

- identify new and emerging weapons, weapons concepts and systems;

- differentiate emerging technologies that may form the basis of weapons in the next 10 years from the speculations and aspirations of weapons designers;

- combine this information with knowledge of biophysical interactions and clinical effects, to identify possible consequences for the DMS in terms of types, patterns and numbers of casualties.

All the information presented in this paper can be found in the open literature, and greater detail on the weapon systems discussed in the paper is available on the Internet.

\section{Emerging Trends}

Weapons using familiar effects such as fragmentation, blast and flame are constantly being refined and enhanced to make them more effective against their targets. Consequently, although 'new' weapons may rely on well established mechanisms for their damaging or wounding effects, the numbers of casualties and the types of injuries they receive may be notably different from those observed in the past. These changes may be quantitative (the same type of injury but more severe), qualitative (for example significant burns from a type of weapon which previously was not perceived as posing a burns threat), or both. Furthermore, the use of new materials in an established type of weapon may produce effects not seen before, such as toxicity or radiation hazard from fragments retained in the tissues.

There are also several types of emerging or potential weapons that aim to use novel methods of injury or incapacitation. Many of these have received a level of publicity which belies the technical and financial problems which must be solved to turn them into practical battlefield systems. Examples range from powerful anti-materiel pulsed lasers (technology demonstrator stage) to radiofrequency (RF) weapons. Consideration of open sources has led to the conclusion that six groups of weapons systems will present notable threats of changing or novel casualty types to UK forces within the next ten years. It should be noted that ballistic threats will continue to be the most common casualtyproducing mechanism for servicemen in any environment. 
Changes in the pattern and numbers of casualties are likely to arise from:

- enhancement of the performance of small arms;

- enhancement of the performance of fragmenting munitions;

- blast weapons;

- laser weapons;

- anti-armour weapons;

- weapons causing burns.

\section{Enhancement of Small Arms}

Small Arms are being developed which fire rounds with increased accuracy, that are designed to penetrate current types of body armour, and have a capability against personnel behind hard cover which would stop current rounds. In cases where body armour is able to defeat the round, the likelihood of severe behind-armour blunt trauma (BABT) will increase.

Large calibre sniper rifles and crew-served machine guns are increasingly fitted with sophisticated sights (with or without laser range-finders) - the aim being to achieve a high probability of hits with the first round or burst. Increasingly, the individual combat weapons (ICW) of infantry in well equipped armies will be fitted with optical sights, laser rangefinders, thermal imagers (TI) and other sensors which are becoming lighter and cheaper. The ensembles of the combat soldier of affluent nations will introduce head-up displays with projected aiming points, and automatic laser rangefinding. The probability of a first round hit at most combat ranges should be greatly increased, with a very short target acquisition time. At present, the vast majority of small arms ammunition is used to suppress the enemy rather than to kill or incapacitate. Developments resulting in greater accuracy may well change this and make small arms fire precise and deadly - a deadliness increased by enhancements of the terminal effectiveness of ammunition upon impact.

Existing small arms performance against body armour can be enhanced by making the whole round (or a smaller diameter core) from harder materials such as tungsten or depleted uranium (DU) and by subtle modifications of its shape. Sub-calibre higher velocity penetrators are even more effective. Large calibre sniper rifles are increasingly employed for long range sniping against men or materiel, and to penetrate cover or body armour - a trend which is gaining strength despite the obvious logistical disadvantages of weight and ammunition standardisation.

Although improvements in body armour may enhance its ability to resist penetration, the problem of Behind Armour Blunt Trauma (BABT) becomes more significant at higher energies, becoming life-threatening with $12.7 \mathrm{~mm}$ rounds. BABT can be reduced by layers of decoupling material and 'standoffs' but optimising these for protection may result in an ensemble which is unwearable in many military scenarios. The issue of BABT is addressed elsewhere in this issue of the journal (Cannon).

Penetration of body armour will result in an increased incidence of wounds exacerbated by bullet deformation/ fragmentation and armour fragmentation more extensive wounds with more tissue damage, multiple wound tracks, more transfer of cloth and contamination, and (possibly) complications from toxicity from fragments of future armours.

These developments are likely to mean that fewer small arms rounds should need to be fired on the future battlefield to produce a casualty - or to put it another way, that small arms fire should become a more effective cause of battlefield casualties. Casualties who survive are likely to have more serious injuries.

\section{Enhancement of fragmentation munitions}

There will be a significant threat from enhanced fragmentation munitions delivered with greatly increased accuracy, producing high velocity fragments intended to penetrate current types of body armour at close range. Precise delivery of such munitions will also enable the fragments to injure soldiers inside vehicles or behind conventional cover. Munitions designed to produce hypervelocity fragments will be a later extension of this threat.

At present, the greatest single cause of battlefield wounds is fragmentation of exploding munitions. There will be a steady continuing trend towards the use of multiple small munitions, each of which uses preformed fragmentation to produce an optimal number of small fragments of a pre-defined size. This trend holds for many hand grenades, and current grenade launchers. The small fragments produced by such munitions lose velocity and thus penetrating ability quickly, within a few metres of their source. They will only penetrate body armour or helmets if the victim is very close to the exploding device. Since these weapons are not aimed precisely, the result is the typical wounding pattern of multiple penetrating wounds of the limbs, with sparing of the vital organs of the protected trunk and head.

This pattern is threatened by the intention of several nations to field improved small calibre (e.g. $20 \mathrm{~mm}$ ) grenade launchers, which use laser range finding linked to very precise instant fusing of each grenade. The small calibre grenades have a high velocity, a flat trajectory, and will be delivered with great accuracy. This will more than compensate in lethality for the reduction in calibre from the currently popular $40 \mathrm{~mm}$. It will be possible to explode grenades precisely above targets lying behind cover. Exploding 


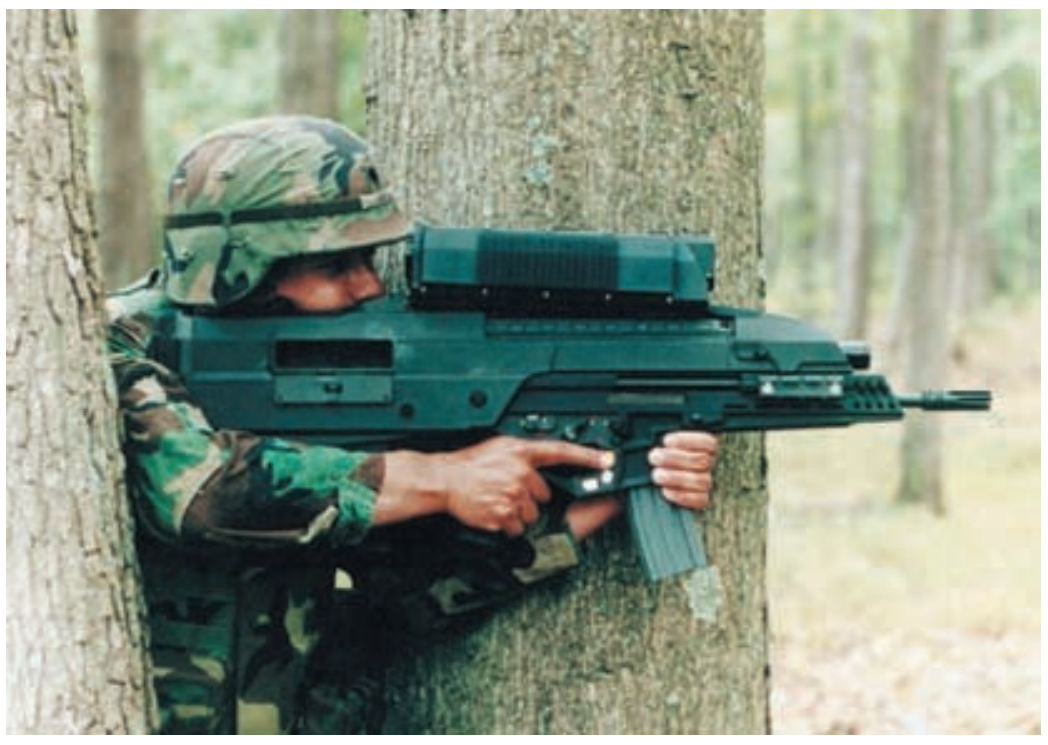

Fig 2. US Objective Infantry Combat Weapon (OICW); note the $20 \mathrm{~mm}$ barrel above the $5.56 \mathrm{~mm}$ barrel.

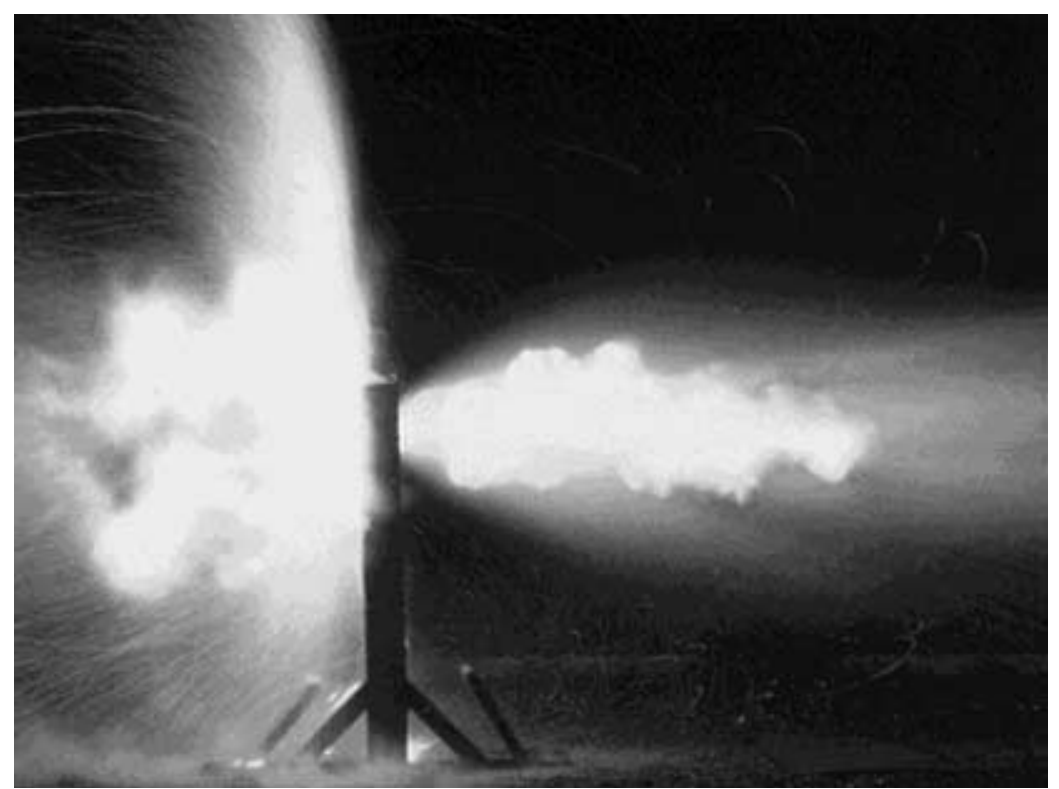

Fig 3. Penetration of armour plate by combined anti-personnel fragmentation/shaped charge warhead.

so close to their targets, the fragments may have a high enough velocity to penetrate body armour. The new $20 \mathrm{~mm}$ grenades will be light, so a large number can be carried. Placing such a weapon in the hands of every infantryman (the intention of several nations, including the USA - see Figure 2) would transform the firepower available to unsupported infantry out to 1000 metres.

Another threat from small calibre grenade launchers is the high-explosive dual purpose (HEDP) round - currently widely available for $30 \mathrm{~mm}$ and $40 \mathrm{~mm}$ grenade launchers. As well as producing optimised fragmentation radially they include a small shaped charge element which fires its jet and slug forward on impact. Ability to penetrate up to $50 \mathrm{~mm}$ of steel armour is typical for $40 \mathrm{~mm}$ grenades (Figure 3). Such grenades are expected to overmatch body armour if impacting directly, resulting in casualties with injuries from small shaped charges as well as fragment wounds.
Further optimisation of fragmentation of all types of exploding munitions can be expected, including more use of flechettes which can penetrate textile armour easily and can be enhanced to penetrate plate armour. Future threats include munitions which produce multiple hypervelocity fragments, from small shaped charges or the MisnaySchardin effect. At present, there is no sign of the appearance of such threats in weaponised form, although the practical principles have been demonstrated.

The DMS can expect a larger number of limb wounds per casualty, and a larger number of wounds of the areas of trunk and head not protected by personal armours, because of the denser fragment swarm close to the munition. There will also be higher energy wounds from fragments of a given size, since fragment velocities are much higher close to an explosion than a few metres away. For the same reason, there may be more wounds of head and trunk from fragments penetrating personal armours. The small precision-fused air-burst munitions may produce a new pattern of wounding in soldiers lying behind cover - multiple wounds of the unprotected buttocks, back of neck, base of spine and backs of the limbs, with injuries to the back of the head and trunk by fragments penetrating their armours. More spinal cord injuries may occur.

\section{Blast threats}

For free field detonation of solid explosives, primary blast lung is uncommon in survivors. Personnel close enough to a military munition to experience sufficient pressure from its point source detonation to produce significant blast lung injury, would normally succumb to multiple fragment wounds. However, 'enhanced blast' weapons which are designed to kill or injure by primary blast effects are now proliferating. They are designed to kill personnel or damage unhardened materiel over a wide area, including within field defences and behind conventional cover. Enhanced blast munitions may overwhelm some forms of cover which would protect against HE or fragmenting munitions - such as field defences and cover normally effective when fighting in built up areas.

Enhanced blast weapons such as fuel air explosives (FAEs), differ from munitions based on conventional condensed high explosive (HE) in a number of respects. Principally, instead of generating a very high overpressure at a point source, which falls off very rapidly with distance from that point, they generate a more uniform overpressure throughout the area covered by the cloud of dispersed fuel. Thus a target at the edge of the cloud of an eighty pound (36 kg) FAE 20-25 feet (6-8 metres) from the device - will experience a potentially lethal overpressure of $\sim 2 \mathrm{MPa}$. At the same distance from the equivalent charge of TNT, the overpressure would be only $\sim 200 \mathrm{kPa}$. Moreover, 
enhanced blast weapons may produce a significantly greater energy output than the equivalent weight of HE. They are very effective anti-personnel weapons, since the blast will diffract round corners and the cloud may enter field defences, negating protective measures effective against conventional HE-based fragmenting munitions. The relatively long duration of the blast overpressure makes them particularly effective for demolishing buildings and fortifications. The fireball from such weapons lasts longer than with the equivalent amount of $\mathrm{HE}$, increasing the burn threat from flame contact and thermal radiation.

Enhanced blast munitions may be deployed deliberately against personnel, or in an anti-materiel role - in which case they will cause 'incidental' damage to any personnel within range. Although mainly available at present in weapons used for land warfare, they are potentially effective against helicopters and some low-flying aircraft. (At high altitudes blast loses its range of effectiveness, so fragmentation is more effective).

These weapons are particularly likely to suddenly produce a large number of casualties with blast, flying debris, translational, crush, burn and combined injuries. Large numbers of casualties with primary blast injury - particularly blast lung - would impose an unprecedented load upon the DMS, since many such cases require intensive treatment if they are to have a good chance of survival. Even small numbers of such cases occurring at one time could rapidly overwhelm available medical resources in terms of both equipment and skilled manpower. Large numbers of casualties with superficial but incapacitating eye injuries are also to be expected.

Blast weapons are discussed in more detail elsewhere in this issue of the Journal (Dearden).

\section{Laser threats}

Lasers and other directed-energy weapons (DEW) can theoretically be weaponised in antipersonnel and anti-materiel roles. Although powerful anti-materiel lasers could be deployed in strategic roles in the next 10 years (e.g. airborne, directed against ICBMs in boost phase), the main battlefield threat will be from relatively low powered lasers directed at sensors and intentionally or incidentally - at servicemen's eyes. Laser 'sensor damage' weapons are relatively cheap and available - and if deployed could potentially produce large numbers of casualties with retinal burns, or the more serious vitreous haemorrhages.

In the Gulf War, and since then in training accidents in the USA, eye injuries have occurred from accidental exposure to laser designators and range finders. Although some nations may install small lasers on all infantry weapons for range finding and aiming within the next 10 years, it is to be expected that these will be 'eye safe'. Lasers on AFVs and on crew-served weapons with a longer range will be more powerful.

Moreover, although 'blinding laser weapons' are subject to an international ban, laser 'sensor damage' weapons are likely to become widespread. They are powerful enough to readily cause large numbers of casualties with retinal burns or the more serious vitreous haemorrhages, especially if the servicemen exposed are using magnifying optical devices. To what extent these will come into tactical use remains to be seen, but the technology is already available at low cost.

Low powered lasers cause retinal burns, the clinical significance of which varies with the size and anatomical position of the lesion. Most retinal burns affect a small area of retina, and off-axis small retinal burns may produce little or no discernible effect on vision. However, even small macular burns can cause serious loss of visual acuity. At present there is no effective treatment or pretreatment, although both of these are the subject of research in USA.

Intermediate powered lasers deliver a few $\mathrm{mJ}$ of energy in a period of micro-, pico-, nano-, or fento-seconds to a small area of retina producing a thermal plasma "explosion" in the retino/choroid layers. This results in a retinal hole, with haemorrhage from the choroid vessels into the vitreous body. This is likely to result in a very poor visual outcome or outright blindness. Casualties with significant vitreous haemorrhage require evacuation and skilled ophthalmological treatment. The production of only a few dozen such casualties would require their prompt evacuation to $\mathrm{UK}$ and the devotion of the facilities of several specialist hospital units. Large numbers (hundreds) of such casualties would severely disrupt the working of the entire NHS ophthalmological service if they were to be given optimal treatment. The implications for specialist equipment and evacuation requirements are profound.

High powered lasers may be responsible for deep burns and burns from ignition of clothing in the future. A $1 \mathrm{~kW}$ continuous wave $\mathrm{CO} 2$ laser operating in the far infra-red (FIR) could produce a skin burn $1 \mathrm{~cm}$ deep over an area of $1 \mathrm{~cm}^{2}$ within one second at a range of several kilometres. Such a powerful FIR beam would, if it struck an eye, deeply burn and rapidly perforate the cornea. Retinal injury might not be a problem, but severe visual disability or blindness would nevertheless be the result. Even a 5W CW $\mathrm{CO}_{2}$ laser operating in the FIR could cause severe corneal burns from a one second exposure, healing with scarring and disabling opacity.

Very high powered lasers - with pulse energies measured in $\mathrm{MJ}$ rather than $\mathrm{mJ}$ - 
already exist in 'technology demonstrator' form. They use plasma generation and shockwave formation for their target effects. Although the potential for destroying antitank battlefield missiles in flight has been demonstrated, such lasers are at present very large, with poor mobility. Consequently, they are unlikely to appear as land battlefield weapons in the near future, although they may appear in a limited strategic role - for example anti-satellite or anti-ballistic missile.

Little is known about the likely effects of such powerful pulsed lasers on humans. Those with very short pulses might result in surprisingly superficial burns, because the most superficial skin layers would be vaporised and this ablation would take up most of the energy, leaving little to be conducted into the deeper layers to cause a deep burn. However, a 'blast' effect on internal organs from shock waves generated by plasma formation at the skin surface - or by the ablation of clothing - is likely to be the most serious injury mechanism.

Ocular effects (retinal burns and vitreous haemorrhages) are likely to be the main concern for the DMS from lasers in the next $5-10$ years. The occurrence of these is not necessarily dependent on fighting an affluent and sophisticated nation, since laser technology is rapidly becoming cheaper, more compact, and more widely available.

\section{Anti-armour weapons}

The armour of modern Armoured Fighting Vehicles (AFVs) is very effective against conventional anti-tank threats, whether based on kinetic energy (KE) or chemical energy (CE). The designers of anti-tank weapons have responded by increasing the power and sophistication of their weapons, and including modifications which specifically target the crews of AFVs. There is a trend towards anti-tank KE rounds and shaped charges of increased size and power, incorporating depleted uranium, aluminium, or other substances intended to cause enhanced behind armour effects. Despite improvements in AFV armour, these are likely to increase casualty rates and produce more serious injuries. A mixture or combination of blast, fragment, eye, and smoke inhalation injuries will occur. The presence of toxic substances from munitions and novel armours in fragments and inhaled material will be a complicating factor.

In response to improvements in AFV armour, a trend is evident towards using larger calibres, higher energy $\mathrm{KE}$ rounds, larger HEAT warheads, and recently towards deliberately enhancing the behind armour effects (BAE) which injure or kill the crew.

In both anti-tank KE rounds and shaped charges, Depleted Uranium (DU) or other substances intended to cause not only improved armour penetration, but also greatly enhanced behind armour casualty generating effects, are increasingly incorporated. Aluminium or magnesium may be included in the skirt of a simple shaped charge to enhance the pyrophoric BAE. Gross overmatching of aluminium armour by KE or HEAT will also produce enhanced pyrophoric effects within the AFV. Anti-tank guided weapons (ATGW) are produced with tandem or even triple warheads to defeat explosive reactive armour (ERA). Triple warheads, with the third component intended to detonate inside the $\mathrm{AFV}$, are likely to produce serious crew casualties with potentially lethal primary blast effects.

The resultant casualties will be more severely injured, despite measures in AFV design aimed at protecting the crew. Injuries from fragment wounds, burns and blast will be more serious. Multiple casualties and a large number of life-threatening combined injuries (fragment wounds, burns, blast effects and smoke/toxin inhalation) are likely to result from overmatching of armour, made worse by enhanced pyrophoric effects. Toxic effects not observed before are likely to cause casualties. Inhalation of oxides of the penetrator, the armour and the penetration and retention in tissues of any of potentially toxic materials, may result in early or late toxic effects from novel components of armours or weapons.

\section{Weapons causing burns}

Although a few weapons are specifically designed to injure personnel or materiel by means of flame or radiated heat, in modern warfare, burns are occurring in increasing numbers as a side-effect of weapons designed primarily to attack vehicles, ships or aircraft themselves. The increasing power of such weapons has led to increasing numbers of combat casualties with burns. Casualties with burns are likely to become more numerous, and individually more severe. Many will not sustain burns in isolation, but also other types of injuries from the attack mechanisms, - for example blast injury, penetrating or blunt trauma, smoke, hot gas or toxic inhalation.

Although there is no apparent trend towards an increasing use of flame weapons such as man-portable flame throwers, they remain in the armouries of many nations, as does napalm, despite bans by international treaty.

There is an increasing tendency for a wide range of weapons to produce burn casualties from flame contact and/or thermal radiation, either deliberately or as a side effect of their primary function - the attack of vehicles, ships or aircraft. Fuel-air explosives and antiarmour munitions are obvious examples. During the 20th century, the increasing power of such weapons has led to increasing numbers of combat casualties with burns (Table 1), and this trend is likely to continue. Individually, the burns will be more severe. Burns from such weapons will generate the largest numbers of casualties in dismounted soldiers and soldiers in AFVs, but the crews 
of ships and aircraft, and embarked personnel, will be subject to the same threats. Many casualties will not have sustained burns in isolation, but also other types of injuries from the attack mechanisms (e.g. blast injury, penetrating or blunt trauma, smoke, hot gas or toxic inhalation). Such 'combined injuries' have a notably worsened prognosis and mortality.

The military environment imposes a number of special clinical management issues for burns casualties, most of them unfavourable for the outcomes for individuals and for the service. At Field Hospitals and on aircraft carriers, there are facilities for essential surgery and a capacity for intensive care and/or ventilation, but only for a limited number of cases. Logistical resources as well as the skilled time of doctors, nurses and medical support staff are put under severe strain by any number of burns casualties. With even modest numbers of serious burns casualties, these limitations must result in rationing and/or suboptimal treatment of individuals. Large numbers of burns casualties apply the same stresses to personnel and logistical resources in the evacuation chain, and back in UK hospitals.

\section{Differences between land, air and sea environments}

Although these types of weapons will produce the largest numbers of casualties in dismounted soldiers and soldiers in AFVs, the crews of ships and aircraft (and embarked personnel) will be threatened by weapons using the same injury mechanisms. Consequently, changes in injury patterns and numbers are likely to affect servicemen in all environments. There are however some variations in relative hazard.

The main threats to aircraft (whether helicopter or fixed wing) and their occupants are ballistic - fragments which may be directed or omnidirectional, bullets from small arms and shells from cannon.

Blast is less of a threat to fast moving fixed wing aircraft, except with precision application by 'hit to kill' missiles, since its effects fall off so rapidly with distance from explosion. Blast effects are also attenuated by altitude. However, helicopters and their occupants could be vulnerable to enhanced blast weapons.

Aircrew have always been perceived as a particularly susceptible target for anti-eye lasers, and aircrew may also be injured by anti-sensor lasers. Aircraft damaged by weapons may burn in the air, or after crashing. Attack helicopters, especially if not moving quickly, are suitable targets for antitank guided weapons (shaped charge warhead) and for KE or explosive shells from the main guns of tanks with more sophisticated fire-control systems. Aircraft may also be vulnerable to future weapons systems such as electromagnetic pulse generators which disable their electronic systems. Ground crews at dispersed airfields are associated with high value targets and are liable to attack by weapons systems of all types.

There does not seem to be any novel attack mechanism specific to sailors, but in ships under attack, they are at risk from: blast overpressure; fragmentation from exploding munitions - and secondary fragmentation from pieces of the ship's structure; displacement injuries within ships attacked by explosive devices; burns; bullets and cannon shells from attacking aircraft, helicopters or small attack vessels; behind armour effects similar to those seen in AFVs, and a relatively high risk of fire and inhalation of smoke or toxic gases. In addition, bridge crew are at risk of eye damage from laser weapons, designators and range finders.

It must not be forgotten that servicemen who are embarked in AFVs, ships or aircraft as passengers, rather than as crew members, are exposed to the same hazards as the crews. However, they usually lack much of the crew's familiarity with surroundings, protective equipment or clothing and knowledge/skills of emergency and escape equipment and drills. This makes them more likely to become casualties.

\section{Summary}

Six groups of changing or emerging weapons systems which are likely to affect the generation of casualties in all types of combat over the next few years have been identified. These have been distinguished from many others which are well publicised but unlikely to be weaponised and encountered in significant numbers before 2010. The likely effects of the 6 groups are summarised in Table 3.

The main factors which will determine the impact of emerging weapons on the DMS the extent to which they proliferate and are encountered by UK servicemen - are unpredictable. They will be affected profoundly by the geographical location and type of conflict. The extent to which casualty numbers and type, can be predicted in advance, and whether suitable medical resources can be predicted and deployed in anticipation, will depend upon the availability and accuracy of intelligence about weapons types and likelihood of use.

The availability of suitable/optimal treatment for certain types of injury (for example blast and burns) from the DMS will depend upon current staffing, equipment and personnel skills. If the deployment and use of new weapons generates overall numbers or numbers of specific types of casualties too large to permit optimal treatment by the staff and equipment possessed by the DMS, the availability and 
Table 3. Implications of emerging weapons systems for the DMS

\begin{tabular}{|c|c|c|c|c|}
\hline $\begin{array}{l}\text { Weapon } \\
\text { type }\end{array}$ & $\begin{array}{l}\text { Casualty } \\
\text { numbers }\end{array}$ & $\begin{array}{c}\text { Different casualty } \\
\text { types }\end{array}$ & $\begin{array}{c}\text { Scenario } \\
\text { specific }\end{array}$ & $\begin{array}{c}\text { Risk of } \\
\text { overwhelming } \\
\text { medical resources }\end{array}$ \\
\hline $\begin{array}{l}\text { Small Arms } \\
\text { Enhancement }\end{array}$ & $\begin{array}{l}\text { More - in some } \\
\text { scenarios }\end{array}$ & $\begin{array}{l}\text { More serious: higher } \\
\text { energy; deliberate } \\
\text { head/torso shots; } \\
\text { armour fragments; } \\
\text { BABT }\end{array}$ & + & Low \\
\hline Fragments & $\begin{array}{l}\text { More - in most } \\
\text { scenarios }\end{array}$ & $\begin{array}{l}\text { More wounds per } \\
\text { casualty overall; } \\
\text { more serious: more } \\
\text { wounds to vital } \\
\text { (armoured) areas, } \\
\text { back \& spine; higher } \\
\text { energy wounds }\end{array}$ & ++ & Low / medium \\
\hline Blast weapons & $\begin{array}{l}\text { More - multiple in } \\
\text { some scenarios; } \\
\text { multiple cas. with } \\
\text { eye injuries }\end{array}$ & $\begin{array}{l}\text { Very different: severe } \\
\text { primary blast injury } \\
\text { rarely seen currently; } \\
\text { combined injuries. }\end{array}$ & +++ & High / Very high \\
\hline Lasers & $\begin{array}{l}\text { More - possibly } \\
\text { multiple in some } \\
\text { scenarios }\end{array}$ & $\begin{array}{l}\text { Very different - } \\
\text { retinal burns; } \\
\text { vitreous } \\
\text { haemorrhages; } \\
\text { psychological effects }\end{array}$ & +++ & $\begin{array}{l}\text { High / Very high for } \\
\text { optimal access to } \\
\text { specialist treatment }\end{array}$ \\
\hline $\begin{array}{l}\text { Anti-armour } \\
\text { weapons }\end{array}$ & $\begin{array}{l}\text { More - in hard- } \\
\text { fought armoured } \\
\text { warfare }\end{array}$ & $\begin{array}{l}\text { More serious overall; } \\
\text { larger primary blast } \\
\text { component; more } \\
\text { eye injuries; } \\
\text { DU/other novel } \\
\text { materials in wounds }\end{array}$ & +++ & $\begin{array}{l}\text { Medium - high at } \\
\text { RAP level }\end{array}$ \\
\hline $\begin{array}{l}\text { Weapons } \\
\text { producing burns }\end{array}$ & $\begin{array}{l}\text { More / multiple - } \\
\text { scenario dependent }\end{array}$ & More serious & ++ & $\begin{array}{l}\text { High - especially at } \\
\text { forward medical } \\
\text { facilities }\end{array}$ \\
\hline
\end{tabular}

speed of evacuation will become critically important issues. However, at worst, large numbers of specific type of casualties (such as retinal haemorrhages) could overwhelm even the resources of the National Health Service, and optimal treatment for all individuals would still not be possible.

\section{Conclusion}

In the light of the real threats posed by emerging changes in weapons and warfare, the DMS should review doctrine for combat casualty care at all levels (including Role 4 the NHS), and constantly update it. Staffing, training and equipment requirements of DMS units should be reviewed regularly. Where necessary, links with the NHS should be revised, with an emphasis on flexibility to deal with unpredictable numbers and/or types of casualties from future conflicts or operations.

The DMS should be in the forefront of developing and introducing new/optimal treatment methods for the casualties produced by emerging weapons. Such methods should be promulgated to civilian practice, not only for the associated benefits for civilian injured, but because the NHS now provides Role 4 care for servicemen injured in large numbers and/or requiring specialist care not available for the DMS.

The review of the emerging trends in weapons and the implications for the DMS and the protection of personnel will continue, to underpin future DMS medical doctrine and the development of new treatment methods. 